\title{
HUBUNGAN ANTARA DUKUNGAN SOSIAL TEMAN SEBAYA DAN KEPERCAYAAN DIRI AKADEMIK DENGAN REGULASI DIRI DALAM BELAJAR PADA MAHASISWA DI UNIVERSITAS $X$
}

\author{
Saka Dewi dan Ruseno Arjanggi \\ Fakultas Psikologi, Universitas Islam Sultan Agung \\ Jl. Kaligawe Raya, KM. 4, Terboyo Kulon, Kota Semarang 50112
}

Email: ruseno@unissula.ac.id

\begin{abstract}
Abstrak
Penelitian ini bertujuan untuk mengetahui hubungan antara dukungan sosial teman sebaya dan kepercayaan diri akademik dengan regulasi diri dalam belajar pada mahasiswa di Universitas X. Penelitian ini menggunakan metode kuantitatif dengan menggunakan teknik cluster random sampling. Subjek dalam penelitian adalah 450 mahasiswa. Alat ukur yang digunakan dalam penelitian ini yaitu skala regulasi diri dalam belajar, skala dukungan sosial teman sebaya dan skala kepercayaan diri akademik. Hasil penelitian menunjukkan bahwa ada hubungan yang signifikan antara dukungan sosial teman sebaya dan kepercayaan diri akademik dengan regulasi diri dalam belajar. Hasil uji korelasi parsial antara dukungan sosial teman sebaya dengan regulasi diri dalam belajar menunjukkan adanya hubungan positif. Hasil korelasi parsial antara kepercayaan diri akademik dengan regulasi diri dalam belajar menunjukkan hasil yang positif. Sumbangan efektif yang diberikan variabel dukungan sosial teman sebaya dan kepercayaan diri akademik dengan regulasi diri dalam belajar adalah 42,1\%.
\end{abstract}

Kata Kunci : regulasi diri dalam belajar, dukungan sosial teman sebaya, dan kepercayaan diriakademik.

\section{CORRELATION BETWEEN PEER SOCIAL SUPPORT AND ACADEMIC CONFIDENCE WITH SELF REGULATED LEARNING IN STUDENTS AT X UNIVERSITY}

\begin{abstract}
The goal of this research is to know relation between social support from peer friend and academic confidence with self regulated learning at University of $X$ students. This research used correlational quantity method with cluster random sampling technique. The subjects in this research were 450 college students. Measuring instruments in this research were self regulated learning scale, social support from peer friend scale, and academic confidence scale. Result of the research show that there are significant relationship between social support from peer friend and academic confidence with self regulated learning. Result of partial correlation test between social support from peer friend and self regulated learning show positive result. Result partial correlation between academic confidence and self regulated learning show positive result. Positive contribution which are given social support from peer friend and academic confidence with self regulated learning are $42,1 \%$.
\end{abstract}

Keyword: self regulated learning, social support from peer friend, and academic confidence.

\section{PENDAHULUAN}

Belajar adalah proses dimana individu menentukan strategi untuk dapat memperoleh pengetahuan, pemahaman, dan keterampilan yang optimal (Siregar, 2016). Proses dari belajar dapat 
berjalan apabila mendapatkan hasil yang disebut dengan hasil belajar. Kendala yang dihadapi dari belajar itu sendiri adalah kurangnya individu dalam mengatur waktu, kurangnnya pengetahuan yang dimiliki, kurangnya mengontrol diri dan kurangnya motivasi yang diberikan (Siregar, 2016).

Kebanyakan individu belajar pada waktu ada tugas dan mendekati ujian. Penelitian mengenai ketidakefektifan belajar individu yang dikemukakan oleh (Aziz, 2016) disebabkan kurangnya motivasi belajar, malas untuk mecari referensi, suka menunda-nunda belajar, jarang mengulang pelajaran, jarang mengerjakan tugas yang diberikan, kurang memiliki kesadaran pentingnya belajar dan kurang dapat mengatur waktu belajar. Hal tersebut membuat regulasi diri dalam belajar individu dikatakan rendah. Untuk meningkatkan belajar individu dapat dilakukan dengan pendekatan regulasi diri dalam belajar.

Regulasi diri dalam belajar itu sendiri adalah suatu pendekatan yang diberikan pada individu untuk menyadari diri sendiri, tugas dalam belajar, strategi untuk belajar dan konteks-konteks pembelajaran yang digunakan (Jakešová \& Kalenda, 2015). Regulasi diri dalam belajar yaitu upaya yang memiliki individu mengenai pengetahuan tentang strategi pembelajaran yang efektif dan bagaimana serta kapan menggunakannya (Ahmadi, 2015). Individu yang dapat mengenali diri sendiri merupakan individu yang memiliki regulasi diri dalam belajar yang baik. Individu yang belajar dengan baik akan mengerti bahwa belajar dapat membuat seseorang mengetahui banyak hal (Zimmerman \& Zimmerman, 2015). Regulasi diri dalam belajar merupakan proses belajar yang dilakukan individu dengan memonitor, mengontrol, memotivasi agar dapat mencapai tujuan yang diharapkan (Adicondro \& Purnamasari, 2011). Pendekatan yang dilakukan merupakan pendekatan regulasi diri dalam belajar dimana pendekatan ini mengacu pada aspek strategi dalam belajar dan motivasi (Pintrich, 1999). Pendekatan ini diharapkan untuk membuat individu lebih memahami diri sendiri agar dapat lebih baik dalam mengatur strategi belajar.

Individu yang memiliki regulasi diri yang baik akan mampu memperluas pengetahuan, memiliki kesadaran akan pentingnya belajar, tidak menunda-nunda belajar, dan mampu mengatur waktu (Adicondro \& Purnamasari, 2011).

Dukungan sosial teman sebaya itu sendiri adalah berupa kenyamanan, perhatian, bantuan atau penghargaan yang diberikan oleh seseorang kepada individu (Putri, 2016). Dukungan sosial teman sebaya yang dimaksud berupa kenyamanan secara fisik sekaligus psikologis yang diberikan teman sebaya (Maslihah, 2011).

Individu yang memiliki dukungan sosial teman sebaya tinggi akan merasa bahwa dirinya diperdulikan oleh orang banyak dan tidak boleh mengecewakan mereka. Dukungan sosial teman sebaya yang tinggi akan membuat individu merasa termotivasi dan lebih semangat dalam belajar agar dapat mencapai tujuan yang diharapkan. Dukungan sosial teman sebaya adalah dukungan pertama kali yang diberikan oleh individu yang memiliki kemungkinan untuk memberikan bantuan dari segi psikologis di dunia perkuliahan (Maslihah, 2011).

Dukungan sosial teman sebaya yang mempengaruhi regulasi diri dalam belajar berupa dukungan penghargaan, dukungan emosional, dukungan instrumental dan dukungan informatif. Apabila dukungan emosionalnya tinggi maka individu akan merasa mendapatkan dorongan yang tinggi dari keluarga maupun temannya-temannya. Apabila individu mendapatkan dukungan instrumental yang baik maka individu akan merasa dirinya memperoleh fasilitas yang mewadahi dan apabila individu memperoleh dukungan informatif yang banyak, maka individu akan merasa memperoleh perhatian 
dan pengetahuan. Apabila individu mendapatkan dukungan penghargaan akan membuat individu merasa lebih percaya diri.

Dukungan sosial teman sebaya sangat berpengaruh terhadap kepercayaan diri individu untuk dapat mengontrol belajar secara baik dan meningkatkan prestasi (Maslihah, 2011)Individu yang memiliki dukungan sosial teman sebaya cenderung mampu menyelesaikan tugas dengan baik dan tidak suka menunda-nunda (Aziz, 2016). Faktanya individu dalam belajar masih merasa ragu dan tidak percaya dengan kemampuan diri sendiri (Vandini, 2015). Individu merasa takut apabila hasil yang di dapat mengecewakan dengan usaha yang telah dia lakukan. Usaha tersebut yaitu dengan belajar maksimal dan meminta bantuan kepada yang lebih tahu (Vandini, 2015).

Dukungan sosial teman sebaya dan kepercayaan diri akademik individu memiliki pengaruh terhadap regulasi diri dalam belajar. Kepercayaan diri akademik itu sendiri adalah kepercayaan yang dimiliki individu akan kemampuan dirinya sendiri dalam memecahkan masalah akademik (Laird, 2014). Individu yang memiliki kepercayaan diri yang tinggi harus yakin dengan apa yang dikerjakan karena sebagai penentu hasil. Selain itu individu harus memiliki kontrol diri yang baik agar dapat menumbuhkan kepercayaan diri akademik yang lebih besar (Sander \& Sanders, 2009).

Kepercayaan diri individu dapat dilihat dari motivasi yang didapatkan. Individu harus dapat menciptakan, mengembangkan dan bertahan dalam motivasinya agar dapar mendapatkan hasil dari belajar sesuai dengan keinginan.

Aspek-aspek yang mempengaruhi kepercayaan diri akademik itu sendiri yaitu nilai, verbalisasi, belajar, kehadiran dalam perkuliahan, pemahaman dan mengajukan pertanyaan. Individu yang memiliki kepercayaan diri akademik akan merasa bahwa dia dapat mengerjakan tugas ataupun ujian dengan maksimal. Selain itu, individu juga akan menghadiri perkuliahan tepat waktu, dapat memahami materi dan dapat menjawab pertanyaan yang diajukan (Sander \& Sanders, 2003). Individu yang percaya diri dalam kemampuan mereka untuk mengatur, melaksanakan, dan memecahkan permasalahan atau tugas mereka di akademisi menunjukkan bahwa dia memiliki kepercayaan diri yang tinggi (T \& Shalini, 2013). Adanya kepercayaan diri akademik, individu akan merasa bahwa dirinya mampu mengerjakan tugas ataupun ujian dengan baik. Selain itu, individu juga dapat mengontrol strategi belajarnya secara efektif agar dapat menghasilkan hasil yang optimal.

Penelitian yang dilakukan oleh Aziz (2016) hasil dari penelitian tersebut adalah ada hubungan yang signifikan antara dukungan sosial teman sebaya dengan regulasi diri dalam belajar pada siswa SMA Yayasan perguruan Bandung Tembung. Selain itu pada penelitian yang di lakukan oleh Adicondro \& Purnamasari (2011) menunjukkan bahwa efikasi diri dan dukungan sosial teman sebaya keluarga memiliki hubungan yang sangat signifikan dengan regulasi diri dalam belajar pada siswa kelas VIII.

Beberapa penelitian yang telah dilakukan tersebut membuat penulis ingin mengetahui bagaimana cara seorang mahasiswa dalam regulasi diri dalam belajar. Peneliti akan melakukan penelitian pada mahasiswa di Universitas $\mathrm{X}$.

Tujuan dalam penelitian ini adalah untuk mengetahui adakah hubungan antara dukungan sosial teman sebaya dan kepercayaan diri akademik dengan regulasi diri dalam belajar pada mahasiswa di Universitas X. Penelitian ini diharapkan dapat memberikan sumbangan bagi disiplin ilmu psikologi, khususnya pada bidang psikologi pendidikan dan diharapkan untuk menambah pengetahuan dan informasi bagi peneliti serta pembaca ataupun pihak-pihak yang akan melakukan penelitian 
selanjutnya mengenai hubungan antara dukungan sosial teman sebaya dan kepercayaan diri akademik dengan regulasi diri dalam belajar pada mahasiswa di Universitas $\mathrm{X}$.

\section{HIPOTESIS}

Berdasarkan pemaparan di atas terdapat 3 (tiga) hipotesis dalam penelitian ini, yakni:

1. Ada hubungan antara dukungan sosial teman sebaya dan kepercayaan diri akademik dengan regulasi diri dalam belajar pada mahasiswa di Universitas $X$.

2. Ada hubungan positif antara dukungan sosial teman sebaya dengan regulasi diri dalam belajar pada mahasiswa di Universitas $X$.

3. Ada hubungan positif antara kepercayaan diri akademik dengan regulasi diri dalam belajar pada mahasiswa di Universitas $\mathrm{X}$.

\section{METODE PENELITIAN}

Populasi penelitian adalah 33.270 mahasiswa di Universitas X. Sementara yang menjadi sampel penelitian yaitu berjumlah 450 mahasiswa. Subjek penelitian dipilih dengan menggunakan teknik cluster random sampling yaitu sampel dipilih dari beberapa kelompok karena terlalu luas. Sugiyono (2010) berpendapat bahwa ukuran sampel yang layak dalam penelitian yaitu antara 30 sampai dengan 500 individu.

Penelitian ini menggunakan tiga skala yaitu skala regulasi diri dalam belajar, skala dukungan sosial teman sebaya dan skala kepercayaan diri akademik. Skala sudah di uci coba dengan hasil reliabilitas skala regulasi diri dalam belajar 0,921. Skala dukungan sosial teman sebaya memperoleh reliabilitas sebesar 0,936. Skala kepercayaan diri akademik memiliki reliabilitas sebesar 0,885 dengan masingmasing responden tiap skala 150.

Skala regulasi diri dalam belajar dibuat berdasarkan aspek-aspek yang telah dikemukakan oleh (Pintrich, 1999) sub skala strategi dan motivasi. Skala ini terdiri dari 52 aitem favourable dan unfavourable yang memiliki koefisien daya beda aitem tinggi yang berkisar antara 0,304 hingga 0,602. Indikator dari regulasi diri dalam belajar yaitu orientasi tujuan intrinsik, orientasi tujuan ekstrinsik, nilai tugas, kendali terhadap keyakinan, efikasi diri untuk belajar dan performansi, kecemasan terhadap ujian, pengulangan/repetisi, perluasan, organisasi materi belajar, berfikir kritis, regulasi metakognitif, manajemen waktu dan lingkungan belajar, regulasi usaha, peer learning, mencari pertolongan.

Dukungan sosial teman sebaya dibuat berdasarkan aspek-aspek yang dikemukakan oleh (Sarafino, 2008) yang terdiri dari dukungan informatif, persahabatan, emosional dan instrumental. Indikator dalam dukungan sosial teman sebaya yaitu bantuan berwujud barang yang diberikan oleh teman, pelayanan yang diberikan oleh teman, dukungan yang diberikan oleh teman, bantuan yang diberikan oleh teman, perasaan empati, perhatian dan kepedulian, dukungan akan ekspresi perasaan dan kehangatan, pemberian nasehat dan saran, pemberian informasi dan petunjuk. Skala dukungan sosial teman sebaya pada penelitian ini terdiri dari 44 aitem favourable dan unfavourable dengan koefisien daya beda aitem berkisar antara 0,316 hingga 0,724 .

Skala kepercayaan diri akademik dibuat berdasarkan aspek-aspek yang dikemukakan oleh (Sander \& Sanders, 2003) terdiri dari nilai, verbalisasi, belajar, kehadiran, pemahaman, dan mengajukan pertanyaan. Skala ini terdiri dari 24 aitem favourable dengan koefisien daya diskriminasi aitem berkisar antara 0,304 hingga 0,602. 
Hubungan Antara Dukungan Sosial Teman Sebaya dan Kepercayaan Diri Akademik Dengan Regulasi Diri Dalam Belajar Pada Mahasiswa di Universitas Negeri Semarang

Proyeksi, Vol. 14 (1) 2019, 84-93

Teknik analisis data yang digunakan adalah teknik regresi berganda dengan menggunakan bantuan SPSS versi 16.0 .

\section{HASIL DAN PEMBAHASAN}

Pengambilan data dilakukan pada tanggal 12 Maret 2018 dengan menyebar skala penelitian kepada responden sebanyak 325 mahasiswa. Proses pengambilan data dilakukan secara langsung dan dari 325 skala yang sudah disebar ternyata yang sudah kembali hanya 307 skala. Skala yang dapat di analisis hanya berjumlah 300 .

Berdasarkan uji normalitas dan uji linieritas pada ketiga variabel yaitu:

Tabel 1. Hasil Uji Normalitas

\begin{tabular}{lcccccc}
\multicolumn{1}{c}{ Variabel } & Mean & $\begin{array}{c}\text { Std } \\
\text { Deviasi }\end{array}$ & Ksz & Sig & P & Keterangan \\
\hline $\begin{array}{l}\text { Regulasi diri dalam } \\
\text { belajar }\end{array}$ & 156,60 & 13,917 & 1,359 & 0,050 & $>0,05$ & Normal \\
$\begin{array}{l}\text { Dukungan sosial teman } \\
\text { sebaya }\end{array}$ & 127,93 & 13,442 & 1,428 & 0,034 & $<0,05$ & Tidak Normal \\
$\begin{array}{l}\text { Kepercayaan diri } \\
\text { akademik }\end{array}$ & 70,4033 & 7,90119 & 1,558 & 0,016 & $<0,05$ & Tidak Normal \\
\hline
\end{tabular}

Tabel 2. Hasil Uji Linearitas

Model Summary and Parameter Estimates

Dependent Variable:Regulasi Diri

Dalam Belajar

\begin{tabular}{|c|c|c|c|c|c|c|c|}
\hline \multirow[b]{2}{*}{ Equation } & \multicolumn{5}{|c|}{ Model Summary } & \multicolumn{2}{|c|}{ Parameter Estimates } \\
\hline & R Square & $\mathrm{F}$ & Df1 & Df2 & Sig. & Constant & B1 \\
\hline Linear & .046 & 14.445 & & 298 & .000 & 128.118 & .223 \\
\hline
\end{tabular}

The independent variable is Dukungan Sosial Teman

Sebaya.

Hasil uji normalitas dapat diketahui bahwa nilai signifikan untuk regulasi diri dalam belajar sebesar 0,050 dan dikatakan data normal. Sedangkan untuk normalitas variabel dukungan sosial teman sebaya memiliki signifikan 0,034 dan kepercayaan diri akademik memiliki signifikan sebesar 0,016 dan data dikatakan tidak normal. Azwar (2012) menyatakan bahwa data berdistribusi normal jika $p>0,05$ atau signifikasi lebih dari 5\%. Pada linieritas nilai signifikannya adalah 0,000 dimana $p<$ 0,05 yang berarti ketiga variabel terdapat hubungan yang linier.

Berdasarkan uji multikolineritas yang untuk mengetahui terjadinya korelasi antara variabel bebas dalam suatu model regresi atau tidak. Model regresi yang baik menggunakan metode pengujian dengan melihat Variance Inflation Factor (VIF) lebih kecil dari 10 dan nilai toleransi lebih dari 1,0 maka penelitian dinyatakan bebas dari multikolinearitas (Priyatno, 2016). Hasil dari pengujian yang telah dilakukan menunjukkan bahwa hasil tolerance sebesar 0,970 dengan nilai Variance Inflation Factor (VIF) pada kedua variabel sebesar 1,031 artinya nilai tersebut lebih kecil dari 10, (Swediati, 2001)sehingga dapat dikatakan bahwa tidak terjadi multikolinearitas pada variabel bebas model 
regresi. Selanjutnya dapat dilakukan dengan uji hipotesis statistik parametrik dengan teknik analisis regresi berganda.

Uji hipotesis dalam penelitian ini menggunakan statistik parametrik karena datanya merupakan data interval dan rasio. Menurut Kerlinger dan Pedhazur (dalam Alsa, n.d.) bahwa asumsi-asumsi yang mendasari teknik analisis regresi yaitu variabel dependen berdistribusi normal dan variabel independen tidak berdistribusi normal, varians skor dependen yaitu sama atau homogen pada skor variabel independen. Asumsi-asumsi menurut Hadi (dalam Alsa, n.d.) menjelaskan bahwa yang mendasari teknik regresi yaitu sampel diambil random dari populasi, variabel tergantung dan variabel bebas bersifat rasio, ordinal dan interval, variabel tergantungnya berdistribusi normal, sifat hubungan antara masing-masing variabel bersifat normal, sesama variabel bebas memiliki korelasi tidak terllau tinggi. Swediati (2001) menjelaskan bahwa statistik parametrik tidak bergantung pada data yang berbentuk normal. Statistik secara parametrik dapat dipakai dan berfungsi dengan baik meskipun asumsi-asumsinya dilanggar, pelanggaran tersebut tidak akan mengganggu hasil analisis.

Berikut kategorisasi data variabel dukungan sosial teman sebaya, kepercayaan diri akademik dan regulasi diri dalam belajar.

Tabel 3. Deskripsi skor regulasi diri dalam belajar

\begin{tabular}{lcc} 
& Empirik & Hipotetik \\
\hline Skor Minimum & 121 & 52 \\
Skor Maksimum & 203 & 208 \\
Mean (M) & 156,60 & 130 \\
Standar Deviasi (SD) & 13,917 & 26 \\
\hline
\end{tabular}

Berdasarkan pada mean empirik yang ada pada norma kategorisasi distribusi, kelompok sampel dalam penelitian dapat diketahui rentang skor sampel berada dalam kategorisasi tinggi yaitu 156,60.

Tabel 4. Kategorisasi skor subjek pada skala regulasi diri dalam belajar

\begin{tabular}{llll}
\hline Norma & Kategorisasi & Jumlah & Persentase \\
\hline $176,8 \leq x \leq 208$ & Sangat tinggi & 26 & $8,7 \%$ \\
$145,6<x \leq 176,8$ & Tinggi & 208 & $69,3 \%$ \\
$114,4<x \leq 145,6$ & Sedang & 66 & $22 \%$ \\
$83,2<x \leq 114,4$ & Rendah & 0 & $0 \%$ \\
$52<x \leq 83,2$ & Sangat rendah & 0 & $0 \%$ \\
\hline
\end{tabular}

Deskripsi skor skala dukungan sosial teman sebaya berdasarkan nilai empirik diperoleh skor minimum sebesar 86 , skor maksimum sebesar 170 , mean sebesar 127,93 dan standar deviasi sebesar 13,442 . Adapun deskripsi skor skala dukungan sosial teman sebaya adalah sebagai berikut :

Tabel 5. Deskripsi skor skala dukungan sosial teman sebaya

\begin{tabular}{lcc}
\hline & Empirik & Hipotetik \\
\hline Skor Minimum & 86 & 44 \\
Skor Maksimum & 170 & 176 \\
Mean (M) & 127,93 & 110 \\
Standar Deviasi (SD) & 13,442 & 22 \\
\hline
\end{tabular}


Hubungan Antara Dukungan Sosial Teman Sebaya dan Kepercayaan Diri Akademik Dengan Regulasi Diri Dalam Belajar Pada Mahasiswa di Universitas Negeri Semarang

Proyeksi, Vol. 14 (1) 2019, 84-93

Berdasarkan norma kategorisasi normal kelompok sampel dalam penelitian ini dapat diketahui bahwa menurut rerata empirik (mean) sebesar 127,93. Hal ini menandakan bahwa mean berada dalam kategori tinggi. Adapun norma kategorisasi yang digunakan sebagai deskripsi data variabel secara keseluruhan dapat dilihat pada tabel berikut:

Tabel 6. Kategorisasi skor subjek pada skala dukungan sosial teman sebaya

\begin{tabular}{lccc}
\hline \multicolumn{1}{c}{ Norma } & Kategorisasi & Jumlah & Persentase \\
\hline $149,6 \leq \mathrm{x} \leq 176$ & Sangat tinggi & 14 & $4,7 \%$ \\
$123,2<\mathrm{x} \leq 149,6$ & Tinggi & 178 & $59,3 \%$ \\
$96,8<\mathrm{x} \leq 123,2$ & Sedang & 106 & $35,3 \%$ \\
$70,4<\mathrm{x} \leq 96,8$ & Rendah & 2 & $0,7 \%$ \\
$44<\mathrm{x} \leq 70,4$ & Sangat rendah & 0 & $0 \%$ \\
\hline & Total & 300 & $100 \%$ \\
\hline
\end{tabular}

Deskripsi skor skala kepercayaan akademik berdasarkan hasil penelitian (empirik) didapatkan skor minimum sebesar 50, skor maksimum sebesar 95, mean sebesar 70,403, dan standar deviasi sebesar 7,901. Adapun deskripsi skor skala kontrol diri adalah sebagai berikut:

Tabel 7. Deskripsi skor skala dukungan sosial teman sebaya

\begin{tabular}{lcc} 
& Empirik & Hipotetik \\
\hline Skor Minimum & 50 & 24 \\
Skor Maksimum & 95 & 96 \\
Mean (M) & 70,403 & 60 \\
Standar Deviasi (SD) & 7,901 & 12 \\
\hline
\end{tabular}

Berdasarkan norma kategorisasi normal kelompok sampel dalam penelitian ini dapat diketahui bahwa menurut rerata empirik (mean) sebesar 70,403. Hal ini menandakan bahwa mean berada dalam kategori tinggi. Adapun norma kategorisasi yang digunakan sebagai deskripsi data variabel secara keseluruhan dapat dilihat pada tabel berikut:

Tabel 8. Kategorisasi skor subjek pada skala kepercayaan diri akademik

\begin{tabular}{llll}
\hline Norma & Kategorisasi & Jumlah & Persentase \\
\hline $81,6 \leq \mathrm{x} \leq 96$ & Sangat tinggi & 26 & $8,7 \%$ \\
$67,2<\mathrm{x} \leq 81,6$ & Tinggi & 158 & $52,7 \%$ \\
$52,8<\mathrm{x} \leq 67,2$ & Sedang & 115 & $38,3 \%$ \\
$38,4<\mathrm{x} \leq 52,8$ & Rendah & 1 & $0,3 \%$ \\
$24<\mathrm{x} \leq 38,4$ & Sangat rendah & 0 & $0 \%$ \\
\hline & Total & 300 & $100 \%$ \\
\hline
\end{tabular}

Hasil uji hipotesis pertama menunjukkan nilai korelasi $R=0,649$ dan $F_{\text {hitung }}=108,090$ dengan signifikansi $0,000(p<0,01)$ yang mengartikan bahwa ada hubungan yang signifikan antara dukungan sosial teman sebaya dan kepercayaan diri akademik dengan regulasi diri dalam belajar pada mahasiswa di Universitas $X$. Koefisien $R$ Square untuk dukungan sosial teman sebaya dan kepercayaan diri akademik diperoleh 0,421 . Hal tersebut dapat dijelaskan bahwa dukungan sosial 
teman sebaya dan kepercayaan diri akademik mempengaruhi regulasi diri dalam belajar sebanyak $42,1 \%$ sedangkan $47,9 \%$ dipengaruhi oleh faktor-faktor lain seperti efikasi diri, motivasi diri.

Hasil uji hipotesis kedua menggunakan uji korelasi parsial terhadap variabel dukungan sosial teman sebaya dan regulasi diri dalam belajar diperoleh ryı-2 $=0,138$ dengan signifikan 0,017 $(p<0,05)$. Hasil tersebut menunjukkan bahwa ada hubungan positif yang signifikan antara dukungan sosial teman sebaya dengan regulasi diri dalam belajar pada mahasiswa di Universitas X. Artinya, semakin tinggi dukungan sosial teman sebaya maka semakin tinggi pula regulasi diri dalam belajar pada mahasiswa Universitas $\mathrm{X}$.

Hasil yang ditunjukkan pada penelitian sebelumnya mengungkapkan bahwa ada hubungan positif yang signifikan antara dukungan sosial teman sebaya dengan regulasi diri dalam belajar (Aziz, 2016). Adanya dukungan sosial teman sebaya dapat membuat individu merasa lebih bertanggung jawab akan proses belajarnya sehingga dapat mengontrol dengan baik. Azmi (2016) mengungkapkan bahwa dukungan sosial teman sebaya sangat berpengaruh terhadap regulasi diri dalam belajar. Sehingga, individu yang mendapatkan dukungan sosial teman sebaya merasa diperhatikan dan mendapatkan motivasi. Individu tersebut juga dapat dengan mudah berdiskusi mengenai permasalahan akademik sehingga dapat menyelesaikan tugas dengan baik. Sarafino (2008) mengungkapkan bahwa dukungan sosial teman sebaya berupa dukungan informatif sangat diperlukan oleh mahasiswa untuk mengembangkan pengetahuan yang belum diketahui agar dapat menyusun strategi belajar secara baik. Selain itu, dukungan persahabatan diperlukan karena setiap individu membutuhkan bantuan dari orang lain dan tidak bisa berdiri sendiri. Dukungan emosional dan instrumental yang diterima oleh individu sangat berpengaruh terhadap perasaan sehingga individu merasa diperdulikan oleh orang lain. Dukungan instrumental berupa bantuan yang diberikan dari teman berupa pelayanan ataupun meminjamkan barang yang dibutuhkan untuk proses belajar sangat berpengaruh terhadap regulasi diri dalam belajar. Sehingga dukungan sosial teman sebaya memiliki peranan yang cukup penting dalam mencapai hasil yang optimal dalam belajar.

Selain itu penelitian yang telah dilakukan oleh Taufiyanti (2017) menjelaskan bahwa ada hubungan yang signifikan antara dukungan sosial teman sebaya dengan regulasi diri dalam belajar. Individu yang mendapatkan dukungan sosial teman sebaya akan memiliki strategi belajar yang baik dan dapat memonitor hasil belajarnya dengan bantuan teman. Penelitian yang dilakukan oleh Mahmudi, dkk (2015) menjelaskan bahwa ada hubungan antara dukungan sosial teman sebaya dengan regulasi dalam belajar, akan tetapi korelasi rendah yaitu $r=0,098$. Hal tersebut diakibatkan karena selain dukungan sosial teman sebaya ada factor-faktor lain yang dapat memengaruhi regulasi diri dalam belajar.

Uji korelasi pada hipotesis ketiga menggunakan uji korelasi parsial. Hasil uji korelasi diperoleh ryı$2=0,627$ dengan signifikan $0,000(p<0,01)$. Hal tersebut menunjukkan bahwa ada hubungan positif yang signifikan antara kepercayaan diri akademik dengan regulasi diri dalam belajar. Artinya semakin tinggi kepercayaan diri akademik maka semakin tinggi pula regulasi diri dalam belajar pada mahasiswa Universitas $\mathrm{X}$.

\section{KESIMPULAN}

Berdasarkan penelitian yang telah dilakukan, dapat ditarik kesimpulan bahwa:

1. Ada hubungan yang signifikan antara dukungan sosial teman sebaya dan kepercayaan diri akademik dengan regulasi diri dalam belajar pada mahasiswa di Universitas $\mathrm{X}$.

\begin{tabular}{l|ll}
\hline & E-ISSN & $2656-4173$ \\
& P-ISSN & $1907-8455$
\end{tabular} 
Hubungan Antara Dukungan Sosial Teman Sebaya dan Kepercayaan Diri Akademik Dengan Regulasi Diri Dalam Belajar Pada Mahasiswa di Universitas Negeri Semarang

Proyeksi, Vol. 14 (1) 2019, 84-93

2. Ada hubungan positif antara dukungan sosial teman sebaya dengan regulasi diri dalam belajar pada mahasiswa di Universitas X. Artinya semakin tinggi dukungan sosial teman sebaya yang diberikan untuk subjek maka semakin tinggi pula regulasi diri dalam belajar pada mahasiswa di Universitas X. Begitupun sebaliknya semakin rendah dukungan sosial teman sebaya yang diberikan untuk subjek maka semakin rendah pula regulasi diri dalam belajar pada mahasiswa di Universitas $\mathrm{X}$.

3. Ada hubungan positif antara dukungan sosial teman sebaya dan kepercayaan diri akademik dengan regulasi diri dalam belajar pada mahasiswa di Universitas $X$. Artinya semakin tinggi kepercayaan diri akademik yang diberikan untuk subjek maka semakin tinggi pula regulasi diri dalam belajar pada mahasiswa di Universitas X. Begitupun sebaliknya semakin rendah kepercayaan diri akademik yang diberikan untuk subjek maka semakin rendah pula regulasi diri dalam belajar pada mahasiswa di Universitas $X$.

4. Penelitian yang dilakukan pada mahasiswa Universitas $X$ memiliki rerata dalam kategori tinggi. Rerata regulasi diri dalam belajar termasuk dalam kategori tinggi, rerata dukungan sosial teman sebaya termasuk dalam kategori tinggi dan rerata kepercayaan diri akademik termasuk dalam kategori tinggi.

\section{DAFTAR PUSTAKA}

Adicondro, N. ; \& Purnamasari, A. (2011). Efikasi diri, dukungan sosial keluarga dan self regulated learning pada siswa kelas viii. Humanitas, $7(1)(1)$.

Ahmadi, A. (2015). Relation between methods of struggling with Stress and the method of solving problem by self-regulated learning. Procedia - Social and Behavioral Sciences, 171, 1273-1279. https://doi.org/10.1016/j.sbspro.2015.01.241

Aziz, A. (2016). Hubungan Dukungan Sosial dengan Self Regulated Learning pada Siswa SMA Yayasan Perguruan Bandung Tembung. Jurnal Pendidikan IImu-IImu Sosial, 103-113.

Azwar, S. (2012). Penyusunan skala psikologi. Jogjakarta: Pustaka Pelajar.

Laird, T. F. N. (2014). College Students ' Experiences with Diversity and Their Effects on Academic Self- Confidence, Social Agency, and ..., (September). https://doi.org/10.1007/s11162-0052966-1

Maslihah, sri. (2011). Studi tentang hubungan dukungan sosial, penyesuaian sosial di lingkungan sekolah dan prestasi akademik siswa SMP IT assyfa boarding school subang jawa barat. Jurnal Psikologi, 10 (2), 103-114.

Pintrich, P. R. (1999). The role of motivation in promoting and sustaining self-regulated learning. International Journal of Educational Research, 459-470.

Putri. (2016). Hubungan antara dukungan sosial dan flow akademik dengan prestasi belajar matematika siswa SMA. Jurnal IImiah Mahasiswa Universitas Surabaya, 5(1), 1-21.

Sander, P., \& Sanders, L. (2003). Measuring confidence in academic study : A summary report.

Sander, P., \& Sanders, L. (2009). Measuring academic behavioural confidence: the ABC scale revisited, 34(1), 19-35. https://doi.org/10.1080/03075070802457058 
Saka Dewi dan Ruseno Arjanggi

Sarafino, E. P. (2008). Biopsychosocial Interactions. sixth edition. USA: John Wiley \& Sons.

Siregar, L. M. (2016). Hubungan antara dukungan sosial keluarga dengan kesulitan belajar. Psychopedia, 1(1), 49-55.

Sugiyono. (2010). Metode penelitian pendidikan. Bandung: Alfabeta.

Swediati, N. (2001). Perlukah uji asumsi statistik dilakukan? Buletin Psikologi, (1), 23-28.

T, A. M., \& Shalini, J. F. (2013). Assessing the Academic Behavioral Confidence of the Secondary School Students. Journal of Humanities and Social Science, 8(1), 41-45.

Vandini, I. (2015). Peran kepercayaan diri terhadap prestasi belajar matematika siswa. Jurnal Formatif, 5(3), 210-219.

Zimmerman, B. J., \& Zimmerman, B. J. (2015). From cognitive modeling to self-regulation : a social cognitive career path. Educational Pshychologist, (July 2013). https://doi.org/10.1080/00461520.2013.794676 